\title{
ENTRE A RELIGIÃO E A POLÍTICA: HANNAH ARENDT, LEITORA DE KIERKEGAARD
}

\author{
Marcio Gimenes de Paula*
}

\begin{abstract}
RESUMO
Hannah Arendt (1906-1975), mulher, judia e pensadora, foi uma das figuras mais desafiadoras do século XX. Sua sólida formação filosóficoteológica e sua percepção aguçada dos totalitarismos foram fundamentais para o respeito adquirido junto ao ambiente acadêmico e político. Múltiplas foram as interpretações de sua obra e os estudiosos seguem, até os dias atuais, debruçados sobre todos os possíveis desdobramentos da sua filosofia. Desse modo, o intuito do nosso trabalho é avaliar aqui uma dessas questões, a saber, a influência de Kierkegaard no seu pensamento. Para tanto, a executaremos através das seguintes subdivisões: (1) um breve panorama da vida e obra da autora; (2) Hannah Arendt, leitora de Søren Aabye Kierkegaard; (3) Hannah Arendt e a época moderna: a questão da dúvida e (4) considerações finais.
\end{abstract}

Palavras-chave: Cristianismo. Filosofia da religião. Hannah Arendt. Kierkegaard. Política.

\begin{abstract}
Hannah Arendt (1906-1975), woman, and Jewish thinker was one of the most challenging of the twentieth century. Its solid theological and philosophical and his keen sense of totalitarianism were fundamental to the respect for purchase from the academic and political environment. Were multiple interpretations of his work and follow the scholars, even today, looking at all the possible consequences of his philosophy. Thus, the aim of our study is to evaluate one of these issues here, namely the influence of Kierkegaard in his thinking. To do so, will run through the following subdivisions: (1) a brief overview of the life and work of the
\end{abstract}

\footnotetext{
* Doutor em Filosofia pela Universidade Estadual de Campinas. Atualmente é professor de Filosofia da Religião no Curso de Filosofia da Universidade de Brasília. E-mail: marciogimenes@unb.br
} 
author, (2) Hannah Arendt, Søren Aabye Kierkegaard reader, (3) Hannah Arendt and the modern era: a question of doubt, (4) concluding remarks.

Keywords: Christianity. Philosophy of religion. Hannah Arendt. Kierkegaard. Politics.

\section{Breve panorama da vida e obra de Hannah Arendt}

Hannah Arendt foi uma das pensadoras mais influentes da política do século XX. Sua época foi marcada pelos imensos desafios de duas grandes guerras mundiais e pelos totalitarismos. Ela nasceu e cresceu na Alemanha, viveu na França quase uma década, mas deixou a Europa para ir para Nova York em 1941, onde permaneceu até a sua morte e onde trabalhou na maior parte do tempo. Desde o início da década de 1950, até os seus últimos dias, ela publicou uma série de obras influentes como, Origens do totalitarismo (1951), um estudo sobre a natureza e as raízes históricas do fenômeno totalitário; A Condição humana (1958), em que realiza uma análise das categorias de base da vita activa. Também se poderia falar de Eichmann em Jerusalém e Sobre a revolução, ambas publicadas em 1963, além de sua obra final inacabada denominada Vida no espírito, publicada três anos depois de sua morte. Além desses trabalhos, ela escreveu também uma série de importantes ensaios sobre temas como a tradição e a modernidade, a autoridade e a liberdade, e acerca da natureza da revolução. Estes ensaios foram publicados, em boa parte, em Entre passado e futuro (1961) e em Homens em tempos sombrios (1968).

Com especialização em filosofia e um notável conhecimento em teologia e no idioma grego, Hannah Arendt recebeu sua educação de vários dos pensadores mais importantes e influentes do século XX como, Romano Guardini (1885-1968), Martin Heidegger (1889-1976), Rudolf Bultmann (1884-1976), Karl Jaspers (1883-1969) e Edmund Husserl (1859-1938). Hannah Arendt nasceu em 14 de outubro de 1906, filha única de Paul e Martha Cohn, ambos com raiz judaica russa. Sua infância pode ser chamada de qualquer coisa, menos de calma e pacífica. Ela tinha três anos, quando sua família mudou-se para Königsberg, então capital da Prússia Oriental. Com apenas sete anos, Hannah Arendt perdeu seu pai e viveu sozinha com a mãe até 1920, quando ela se casou novamente. Hannah Arendt frequentou o colégio em Königsberg e ingressou na Universidade de Marburg em 
1924, onde teve a chance de estudar com Heidegger. Em 1925, ocorreu o seu célebre relacionamento amoroso com o filósofo, com quem manteve relações intelectuais e correspondência em todo o tempo. No ano seguinte, muda-se para a Universidade de Heidelberg e lá tem os primeiros contatos com Jaspers, seu futuro orientador na tese sobre o conceito de amor em Santo Agostinho (354-430), que será publicada em 1929. Ainda em 1926 e já adentrando em 1927 - vai para a Universidade de Freiburg e lá mantém contato com Husserl. Em 1929, a pensadora se casa com Günther Stern (1902-1992) e se muda para Berlim De 1933 em diante, adere ao movimento sionista e empreende viagem para a Palestina entre 1935 e 1938. Em 1936, conhece Heinrich Blücher (1899-1970), com quem se casará em 1941, após se divorciar do seu primeiro marido em 1937. Entre os anos 1940 e 1960, podemos dizer que ocorreu o auge da sua produção acadêmica e, após intensa atividade acadêmica e participação política efetiva nos principais debates do século XX, a pensadora, que foi professora da $\mathrm{New}$ School for Social Research de Nova York desde 1967, falece em 1975.

\section{Hannah Arendt, leitora de Søren Aabye Kierkegaard}

Dois autores foram fundamentais para a leitura kierkegaardiana de Arendt. O primeiro é o tradutor Theodor Haecker (1879-1945), que vai verter Kierkegaard para o alemão e o torna disponível a uma série de filósofos de língua germânica do século XX, dentre os quais podemos citar, além da própria autora, pensadores como Theodor W. Adorno (1903-1969), Georg Lukács (1885-1971), Walter Benjamin (1895-1942), Heidegger, Karl Löwith (1897-1973) e Jaspers. O segundo foi Jaspers. Arendt, que foi sua aluna e orientanda na tese $O$ Conceito de amor em Santo Agostinho, certamente era sabedora dos elogios do seu mestre a Kierkegaard, presentes em sua obra $A$ situação espiritual do nosso tempo:

A primeira crítica acabada de sua sociedade, distinguindo-se por sua seriedade de todas as críticas precedentes, foi trazida por Kierkegaard. Sua crítica é a primeira que ouvimos como uma crítica também para nosso tempo; é como se houvesse sido escrita ontem (JASPERS, 1931, p. 11). 
Certamente, alguns dos seus comentários foram compartilhados não apenas por Arendt, mas também por Husserl, Heidegger, Löwith. Assim como também estes mesmos comentários foram rechaçados por Lukács na sua conhecida obra $O$ assalto da razão. Ali o filósofo húngaro pontuará que, no seu entender, Löwith se equivoca ao colocar Kierkegaard e Karl Marx (1818-1883) na mesma perspectiva, bem como se equivoca ao abordar todos os pós-hegelianos como se esses fossem um grupo unitário (LÖWITH, 1969).

Seguindo a pista agostiniana da relação entre fé e razão, o salto da fé em Kierkegaard parece se constituir no interesse da filósofa desde o seu trabalho desenvolvido sob a orientação de Jaspers. Aliás, cabe aqui um registro instigante, que prova que tal coisa é ainda mais antiga na vida da pensadora. A filósofa, que, na verdade recusava tal nomenclatura, e preferia se nomear como uma estudiosa de teoria política, diz isso numa curiosa entrevista concedida a Günter Gaus (1929-2004) - transmitida pela TV em 1964. Nela também afirma categoricamente perseguir, desde quando tinha quatorze anos, temas filosóficos e teológicos, ou seja, começou pela filosofia ainda que depois, segundo sua definição, tenha mudado sua área de interesse. Ela relata ao seu entrevistador que, após a leitura de Immanuel Kant (1724-1804) e da Psicologia das concepções do mundo de Jaspers, partiu para a leitura do autor dinamarquês: "Então li Kierkegaard, e aquilo se encaixou" (ARENDT, 2008, p. 38).

Mais ainda do que isso, Arendt não possui nenhum tipo de preconceito com temas teológicos e sempre os relacionou com temas de filosofia, tal como aprendeu também com Bultmann, um dos seus exprofessores:

Eles se encaixavam de tal forma que, para mim, ambos eram uma coisa só. Eu só tinha alguns receios sobre a maneira de lidar com isso, se você é judeu... como proceder. Eu não fazia idéia, sabe. Tive sérios problemas que depois se resolveram sozinhos (ARENDT, 2008, p. 39).

Por isso, num belo texto publicado em 1965 e totalmente dedicado ao cristão Angelo Giuseppe Roncalli, ou seja, o Papa João XXIII (18811963), a pensadora afirma novamente a importância de Kierkegaard e dos desafios de se conjugar filosofia e teologia: 
As gerações de intelectuais modernos, na medida em que não eram ateístas - isto é, tolos que pretendiam saber aquilo que nenhum homem pode saber -, foram ensinadas por Kierkegaard, Dostoievski, Nietzsche e seus inumeráveis seguidores, dentro e fora do campo existencialista, a considerar 'interessantes' a religião e as questões teológicas (ARENDT, 1987, p. 65).

Para além dos seus interesses na discussão entre fé e razão, Arendt também se interessa pela importância que o pensamento kierkegaardiano confere ao tema do indivíduo. Nesse sentido é que podemos entender sua crítica ao mundo burguês e como a autora consegue se aproximar daquilo que Kierkegaard acreditava ser a escolha de Deus a fim de que ele servisse de exemplo aos homens. Tal atitude, num tempo burguês de profunda acomodação, é vista por ela como algo tão importante como a ideia de destino para Napoleão Bonaparte (1769-1821) e de história para Georg Wilhelm Friedrich Hegel (1770-1831) ${ }^{1}$. Assim, no entender da pensadora, Kierkegaard é o iniciador da moderna filosofia da existência e seus méritos consistem em haver debatido com grandes nomes do seu tempo e proposto alternativa para suas filosofias:

A filosofia moderna da existência começa com Kierkegaard. Não existe um único filósofo existencial que não se mostre influenciado por ele. Como sabemos, o ponto de partida de Kierkegaard foi uma crítica a Hegel (e, podemos dizer, um descaso deliberado por Schelling, a cujas aulas ele havia assistido). Contra o sistema hegeliano, que pretendia abranger e explicar a 'totalidade', Kierkegaard propôs o 'individual', o ser humano único, que não encontra lugar nem sentido numa totalidade controlada pelo espírito universal. Em outras palavras, o ponto de partida de Kierkegaard é o sentimento do indivíduo de estar perdido num mundo totalmente explicado (ARENDT, 2008, p. 202).

Nesse mesmo sentido, Sócrates (469-399 AC) será, em sua busca pela filosofia do indivíduo, o seu grande modelo, seu guia nessa procura pela verdade da subjetividade. A partir da afirmação da tese

1 Tal afirmativa aparece de modo claro num texto de Arendt dedicado a Kafka, denominado Fraz Kafka: uma reavaliação (publicado na coletânea Compreender - 2008). 
da importância da subjetividade humana e de compreender que, ao seu modo, cada homem pode ser, ao mesmo tempo, uma exceção quando ouve o chamado de Deus e que a consciência da morte e da finitude se torna algo importante para o próprio filosofar, Kierkegaard se reapropria da herança socrática e agora, lendo-a com a chave do cristianismo, traz uma nova interpretação para o conceito de instante.

Para Arendt há aqui uma singular curiosidade: uma possível comparação entre Marx e Kierkegaard. Segundo ela, ambos partem do fato de que os homens, na medida em que são seres singulares, dão suas respostas num determinado instante da sua existência. Contudo, Marx conduz sua explicação para a política e Kierkegaard a aprofunda na psicologia. Por isso, Marx acredita que o homem pode mudar determinadas estruturas e Kierkegaard reafirma sua crença na subjetividade humana. $\mathrm{O}$ fato concreto é que Marx, aos olhos de Arendt, não parece se desvencilhar da filosofia hegeliana e, mesmo querendo invertê-la, se coloca sob sua proteção. Já Kierkegaard parece desafiá-la mais efetivamente e, nesse sentido, parece ter sido mais audacioso do que Marx: "Kierkegaard teve muito mais importância do que Marx para o desenvolvimento posterior da filosofia, porque manteve sua desesperança em relação à filosofia" (ARENDT, 2008, p. 204).

Arendt no seu texto Søren Kierkegaard, publicado na coletânea Compreender, parece apontar para duas recepções do autor dinamarquês. A primeira é uma recepção um tanto esquecida, isto é, a obra do pensador fica restrita a Dinamarca e demora muito tempo a chegar ao restante da Europa. A segunda é a recepção que efetivamente se conhece, sobretudo na Alemanha, entre os anos 1920 e 1930. Muito por conta das traduções de Christoph Schrempf (1860-1944) e, posteriormente, Häcker. Tal fase revela um Kierkegaard tipicamente defensor do autêntico cristianismo e em luta franca e aberta contra a cristandade.

Contudo, notadamente no contexto alemão da Segunda Guerra, onde o ideal cientificista parece falar cada vez mais alto, Kierkegaard é relegado a um segundo plano. Afinal, não se podia dar aqui crédito a um mestre da desconfiança se o interesse era exatamente afirmar peremptoriamente algumas coisas. Por isso, "foi apenas nos anos pós-guerra, quando surgiu uma vontade de demolir estruturas intelectuais ultrapassadas, que a 
Alemanha, veio a oferecer um solo onde o pensamento kierkegaardiano poderia lançar raízes" (ARENDT, 2008, p. 74). Com efeito, Hannah Arendt também acredita que Friedrich Nietzsche (1844-1900) é uma espécie de preparador do terreno germânico onde Kierkegaard pôde florescer:

Nietzsche e a filosofia da vida (Lebensphilosophie), Bergson, Dilthey e Simmel haviam preparado o terreno para Kierkegaaard na Alemanha. Com Nietzsche, houve a primeira ameaça aos postulados fundamentais da filosofia sistemática, pois a destruição nietzschiana dos velhos pressupostos psicológicos revelou as energias extrafilosóficas, psíquicas e vitais que de fato levavam os filósofos a filosofar. Essa revolta de um filósofo contra a filosofia iluminava a situação do próprio filosofar e insistia que o filosofar era filosofia. Isso significava o resgate da subjetividade do indivíduo (ARENDT, 2008, p.74).

Kierkegaard configura-se claramente aqui como o autor crítico do cristianismo do seu tempo e crítico do sistema hegeliano. A questão do indivíduo, um tema moderno por excelência e presente nos melhores debatedores da época, é aqui recuperada juntamente com uma investigação profunda sobre interioridade e subjetividade. Tais temas remontam tradições ainda mais longínquas como a tradição socrática e a agostiniana. A pergunta que Arendt aqui se coloca é se a Alemanha do pós-guerra foi capaz de assimilar a filosofia kierkegaardiana, ou seja, se ela foi capaz de inserir, no debate filosófico, tais questões e temas tão marcantes como, paradoxo, existência e a crítica do próprio conceito de história.

Para Arendt, Kierkegaard não deixa de ser o pai de uma espécie de ceticismo radical que atinge tanto católicos como protestantes. Tal aspecto do pensamento kierkegaardiano não advém apenas de seus escritos, mas antes da sua biografia pessoal e do seu exemplo. O autor vive numa sociedade que já se encaminha para uma profunda secularização, mesmo na Dinamarca, sempre tão marcada e regida pelos ditames eclesiásticos. Com efeito, "Kierkegaard foi o primeiro pensador a viver num mundo muito semelhante ao nosso, isto é, um mundo totalmente secularizado oriundo do Iluminismo" (ARENDT, 2008, p. 75).

O desafio de Kierkegaard diante da secularização parece, portanto, 
ainda maior que o desafio dos primeiros tempos do cristianismo, onde esse era claramente seguido por uma minoria. Nos tempos modernos, onde a secularização e a desconfiança se instalam não é preciso apenas afirmar o cristianismo, mas é preciso afirmá-lo quando todos o negam através de teses e argumentos muito bem elaborados. Por isso, "ser radicalmente religioso em tal mundo significa estar sozinho não só no sentido em que a pessoa se posta diante de Deus, mas também no sentido de que ninguém mais se posta diante de Deus" (ARENDT, 2008, p. 76). Em outras palavras, não parece mais haver comunidade cristã, mas alguns indivíduos que ainda buscam manter a integralidade da mensagem cristã.

Contudo, ao mesmo tempo, esse eu não é um egoísmo, mas uma renúncia ao mundo temporal, um voltar-se para Deus. A existência se realiza plenamente em Deus e nele podemos nos realizar ou dele podemos nos afastar, por decisão da nossa vontade. Há aqui uma tensão permanente entre o desejo humano e a submissão do desejo ao divino. Tudo isso aparece em Kierkegaard cercado pelos pseudônimos, pela lógica e pela estratégia própria de cada um deles. Temas estéticos e pseudônimos podem parecer, num primeiro olhar, fortemente influenciados pelo romantismo, mas, para Arendt, tanto Kierkegaard como Nietzsche representam superações do romantismo. Em ambos os autores, pode-se perceber a transformação de meros problemas estéticos em problemas éticos e de existência. Nesse sentido, "Kierkegaard pagou com sua vida as dívidas que o romantismo havia acumulado com uma liberalidade descompromissada" (ARENDT, 2008, p. 77).

\section{Hannah Arendt e a época moderna: a questão da dúvida}

Ao analisar o conceito de tradição e época moderna, Arendt parte, de modo inevitável, de Platão (428/427-348/347 AC) e de Aristóteles (384-322 AC). Contudo, seu foco principal será aqui examinar três dos principais intérpretes da modernidade: Marx, Kierkegard e Nietzsche. Curiosamente, diferentemente de uma certa tradição canônica, que coloca Marx, Nietzsche e Sigmund Freud (1856-1939) como os célebres mestres da suspeita, Arendt parece apostar aqui no pensador dinamarquês como alguém digno de ocupar o posto do pai da psicanálise. 
No seu entender, Marx seria um autor moderno na medida em que articula uma separação entre filosofia e política, coisa que não era feita pelos antigos gregos. Segundo Arendt, o pensador alemão prioriza o transformar em detrimento do interpretar, tal como se pode notar na $11^{\mathrm{a}}$ tese das Teses contra Feuerbach: "Os filósofos se limitaram a interpretar o mundo diferentemente, cabe transformá-lo" (MARX, 1978, p. 53). Desse modo, será seguindo esta mesma pista que a pensadora avalia que Kierkegaard, Marx e Nietzsche são autores que desafiam os pressupostos básicos da religião tradicional:

O fim de uma tradição não significa necessariamente que os conceitos tradicionais tenham perdido seu poder sobre a mente dos homens. Pelo contrário, às vezes parece que esse poder das noções e categorias cediças e puídas torna-se mais tirânico à medida que a tradição perde sua força viva e se distancia a memória de seu início; ela pode mesmo revelar toda a sua força coercitiva somente depois de vindo seu fim, quando os homens nem mesmo mais se rebelam contra ela. Essa, pelo menos, parece ser a lição da tardia colheita de pensamento formalista e compulsório, no século XX, que veio depois que Kierkegaard, Marx e Nietzsche desafiaram os pressupostos básicos da religião tradicional, do pensamento tradicional e da Metafísica tradicional invertendo conscientemente a hierarquia tradicional dos conceitos. Contudo, nem as conseqüências do século XX nem a rebelião do século XIX contra a tradição provocaram efetivamente a quebra em nossa história. Esta brotou de um caos de perplexidades de massa no palco político e de opiniões de massa na esfera espiritual que os movimentos totalitários, através do terror e da ideologia, cristalizaram em uma nova forma de governo e dominação. A dominação totalitária como um fato estabelecido, que, em seu ineditismo, não pode ser compreendida mediante as categorias usuais do pensamento político, e cujos 'crimes' não podem ser julgados por padrões morais tradicionais ou punidos dentro do quadro de referência legal da nossa civilização, quebrou a continuidade da História Ocidental. A ruptura em nossa tradição é agora um fato acabado. Não é resultado da escolha deliberada de ninguém, nem sujeita a decisão ulterior (ARENDT, 2000, p. 53-54). 
Dado que a tradição ainda não acabou na mente dos homens, tal como sugere Arendt, o máximo que o século XIX consegue fazer é apenas questioná-la no pensamento:

A rebelião contra o século XIX permaneceu estritamente no interior de um quadro de referência tradicional; e, ao nível do mero pensamento, que dificilmente poderia se preocupar, então, com mais que as experiências essencialmente negativas da previsão, da apreensão e do silêncio ominoso, somente a radicalização, e não um novo início e reconsideração do passado, era possível (ARENDT, 2000, p. 55).

Por isso é que, curiosamente, Kierkegaard, Marx e Nietzsche são também, e ao seu modo, hegelianos. Desse modo, podemos perceber aqui que, mesmo em Arendt, Kierkegaard é visto primariamente, como pudemos notar em seu texto $O$ que é filosofia da existência? (da coletânea Compreender) como um anti-hegeliano e aqui sua interpretação, ainda que com reservas, o aproxima mais do filósofo alemão. Em todos eles, mesmo em Kierkegaard e em Nietzsche, com todas as suas críticas, o tema da história universal passa a ocupar o lugar outrora destinado à tradição:

Kierkegaard, Marx e Nietzsche permaneceram hegelianos na medida em que viram a História da Filosofia passada como um todo dialeticamente desenvolvido; seu grande mérito está em que radicalizaram essa nova abordagem ao passado da única maneira em que ela podia ser ainda desenvolvida, isto é, questionando a tradicional hierarquia conceitual que dominara a Filosofia Ocidental desde Platão e que Hegel dera ainda por assegurada (ARENDT, 2000, p. 55-56).

Com efeito, podemos afirmar que os três autores realizam um salto contra a tradição. Kierkegaard opera um salto da dúvida para a fé. Entretanto, mais do que realizar isso, ele altera a tradicional relação entre razão e fé estabelecida desde René Descartes (1596-1650), oferecendo ainda uma crítica à modernidade descrente da sua época. Marx salta, como podemos observar, da teoria para a ação, da interpretação do mundo para a sua transformação. $O$ salto nietzschiano caracteriza-se por inverter o platonismo e o cristianismo como platonismo popular numa afirmação da vida e das potências humanas. 
Arendt aponta, com extrema clareza, que o desejo de Kierkegaard é apenas afirmar a dignidade da fé contra a razão e o raciocínio. Cabe, contudo, esclarecer que não se trata aqui, em momento algum, de defesa do irracionalismo ou de fideísmo simplório. O que o autor dinamarquês parece afirmar é que a razão humana não é capaz de nos conduzir a uma explicação cabal de todas as coisas e, por isso mesmo, a fé só pode ser entendida como absurda ou paradoxal. Kierkegaard também não parece combater no mesmo campo do debate teórico da ciência moderna e do racionalismo, logo não se pode tomá-lo como irracionalista. Sua questão é muito mais localizada no campo da interioridade humana. Por isso, para ele, tanto se equivoca uma religião que deseja se afirmar racionalmente como um racionalismo científico que deseja explicar tudo, a qualquer preço, inclusive a fé e a religião.

Segundo Arendt, o primeiro dado que temos que notar é que, ao saltar da dúvida para a crença, o autor dinamarquês traz a própria dúvida para a discussão religiosa. Tal tradição faz com que o pensador possa ser visto em paralelo com grandes autores cristãos como Blaise Pascal (16231662), por exemplo. Por isso é que a autora explora claramente tal dado em A condição humana:

A principal característica da dúvida cartesiana é a sua universalidade, o fato de que nada, nenhum pensamento ou experiência, dela escapa. Talvez ninguém tenha explorado suas verdadeiras dimensões com maior honestidade que Kierkegaard, quando este se lançou - não da razão, como ele julgava, mas da dúvida - para a crença, levando assim a dúvida ao próprio cerne da religião moderna (ARENDT, 2007, p. 288).

Desse modo, sua contribuição também afirma, num tempo em que ciência moderna se estabelece como forte crítica da religião, uma transferência do debate do campo das observações para o campo da interioridade, único local onde a crença pode se desenvolver e se nutrir. Notemos aqui que tal pista, além de demonstrar a herança agostiniana, tem a sua repercussão também na literatura contemporânea, como em Fiodor Dostoiévski (1821-1881), por exemplo, tal como aponta a autora alemã:

Não há sintoma mais claro desta moderna situação religiosa que o fato de Dostoiévski, talvez o mais vívido psicólogo das crenças religiosas 
modernas, ter retratado a fé pura no caráter de Mishkin, 'o idiota', ou de Alioscha Karamázov, que é puro coração porque ingênuo (ARENDT, 2000, p. 57).

Curiosamente, segundo Arendt, Pascal e Kierkegaard, ao introduzirem o tema da dúvida no debate religioso, terminam por minar estruturas que não tinham sido atingidas nem pelo ateísmo do século XVIII e nem pelo materialismo do século XIX. Aqui reside precisamente o desafio da sua filosofia:

(Pois o que minou a fé não foi o ateísmo do século XVIII nem o materialismo do século XIX - cujos argumentos são, muitas vezes, vulgares, e quase sempre facilmente refutáveis pela teologia tradicional - mas o descrente interesse pela salvação em homens genuinamente religiosos, a cujos olhos o conteúdo e a promessa tradicionais do cristianismo se haviam tornado "absurdos") (ARENDT, 2007, p. 332$333)$.

\section{Considerações finais}

O intuito do nosso breve trabalho foi apenas fornecer um panorama de como o pensamento de Kierkegaard foi fundamental para o desenvolvimento da filosofia de Hannah Arendt. Mais do que simplesmente mostrar afinidades ou dados biográficos da pensadora, nosso objetivo foi retratar como, através de seus trabalhos e das suas próprias declarações, podemos constatar a evidente presença do pensador dinamarquês em seus escritos. Se observarmos com atenção algumas das obras da pensadora, poderemos constar a abundante presença do autor dinamarquês e sua importante interlocução na feitura do seu próprio pensamento. Tal fato nem sempre pode ser percebido tão claramente. A respeitável coletânea The Cambridge Companion to Hannah Arendt (Vila, 2000), por exemplo, nos seus quatorze capítulos, escritos por estudiosos da obra da autora, não faz uma menção sequer ao nome do pensador dinamarquês. Tal fato é, segundo julgamos, imperdoável dado que na obra da pensadora Kierkegaard possui um importante e destacado lugar.

A conjugação que Arendt faz entre teologia e filosofia está exatamente no cerne do debate kierkegaardiano e dentro da melhor 
herança da filosofia moderna que, desde o Tratado teológico-politico de Baruch de Espinosa (1632-1677) tem sido fundamental para discutir temas de política, de religião, de teologia e de investigações em torno do tema da secularização. Sua crítica da sociedade e sua teoria política, que busca remontar a gênese do totalitarismo e sua constante preocupação com os valores democráticos, podem ser igualmente observada no panorama político do século XIX e nos debates sobre a nem sempre pacífica relação entre religião e sociedade.

A crítica kierkegaardiana à Igreja, à cultura e ao Estado dinamarquês de sua época era muito bem conhecida pela filósofa e, evidentemente dentro dos limites de sua época, julgamos que ela pode muito bem compreender os desafios colocados por Kierkegaard para a filosofia, para a política e para a religião.

\section{Referências}

ARENDT, H. Compreender - formação, exílio e totalitarismo. São Paulo: Companhia das Letras, 2008.

. A condição humana. Rio de Janeiro: Forense, 2007. . Entre o passado e o futuro. São Paulo: Perspectiva, 2000.

1987. . Homens em tempos sombrios. São Paulo: Companhia das Letras,

JASPERS, K. Die geistige Situation der Zeit. Berlin: Walter de Gruyter, 1931.

LÖWITH, K. De Hegel à Nietzsche. Paris: Gallimard, 1969.

MARX, K. Teses contra Feuerbach (Os Pensadores). São Paulo: Abril Cultural, 1980.

Vila, D. (Ed.). The Cambridge Companion to Hannah Arendt. Cambridge: Cambridge University Press, 2000.

Data de registro:03/12/2011

Data de aceite:28/03/2012 